\title{
NATURALEZA E HISTORIA EN EL TRACTATUS DE JUAN DE PARÍS
}

Antonio D. Tursi*

SÍNTESIS - El Tractus de regia potesate et papali (c. 1302/3) de Juan Quidort de paris O. P. tiene como objetivo principal, como dice en el promeio, considerar "circa potestatem ecclesiaticorum pontificum" con el fin de refutar todo argumento que pretenda otorgar al papado "dominum in rebus". or nuestra parte trataremos de rastrear en los argumnentos que Juan esgrime de contrapeso para con la teocracia papal los elementos que nos permitan reconstruir su concepción de la naturaleza e historia del hombre. Al respectose haa señalado la deuda que posee el Tractatus respecto de la corriente naturalista que arranca con los textos aristotélicos redescubiertos y especialmente por los comentarios tomísticos a los "libri morales Aristotelis". Sin embargo, a partir de una lectura minuciosa del misto no se sigue que Juan sea un autor aristotélico. La recurrencia a determinadas afirmaciones de Aristóteles responden, en rigor, más a la moda que a una fundamentación sobre la naturaleza del hombre y la sociedad. Antes bien, para ésta Juan recurre a la tradición estoicociceroniana y especialmente a los textos de Cicerón de más amplio rendimiento ético-político en el medioevo, el De inventione (Vetus Rhetorica) y el De officiis. Así, la versión latina, "homo animal politicum et sociale", de la definición aristotélica es tematizada por Juan no aristotélica, sino ciceronianamente. Hay tres etapas, una bestial (multitudo), outra social (societas) y la tercera civil (civitas) que se suceden progresivamente. Cada una de las cuales supera la anterior; huarda cada una determinadas caraterísticas $y$, con todo, poseen un denominador común, detonante tanto de conflictos como de derecho: la propiedad privada. PALABRAS-CLAVE - Juan de Paris. Filosofia Política. Naturaleza. Historia.
ABSTRACT - The Tractatus de Regia Potestate et Papali (1302/3) by john Quidort of Paris O. P. has a principal aim, as he states in the preface, to consider "circa potestatem ecclesiasti corum pontificum" with the intetion to refute arguments on the pretension to give the papacy "dominium in rebus". As for us, we will try to seek in the arguments John wields as a counterpart to papal theocracy the elements that permit us rebuild his conception about the nature and history of mankind. On this matter it has been signaled the debt the Tractatus has with the nsturalistic current that begins at the thomistic commentaries to the "libri moralis Aristotelis". Still fron an accurate reading of the Tractatus there is no reason to establish that John is an Artistotelian author. The recurrence to specific affirmations of Aristotle are due more to fashion than to a foundation on the nature of man and society. So much so that for that foundation John appeals to the stoic-ciceronian tradition and specially to the texts by Cicero of amplest effectiveness on Ethics and Politics during the Middle Age: De Inventione (Vetus Rhetorica) and De Officiis. In such a way the latin translation "homo animal politicum et sociale" from the aristotelian definition is treated not in the Aristotelian way but in the Ciceronian one. There are three stages, one bestial (multitudo), another social (societas) and a third one civil (civitas) which are progressively aligned. Each of them surpasses the former; each of them keeps a definite characteristic; still they posses a common denominator, detonator of both conflicts and law: private property.

KEY WORDS - John of Paris. Political Philosophy. Nature. History.

* Universidad de Buenos Aires.

\begin{tabular}{l|l}
\hline VERITAS & Porto Alegre
\end{tabular} 
En el Tractatus de regia potestate et papali (c.1302-3) del maestro dominico Juan Quidort de París se encuentra la convergencia entre la concepción aristotélica de la naturaleza del hombre como "animal politicum" que Juan lee en textos de Tomás de Aquino, especialmente De regno I, 1-3, y otra cierta concepción de la naturaleza humana cuya fuente es un pasaje bien acotado de Cicerón, De inventione I, 2. Sobre la influencia de ambas concepciones ya se ha insistido. ${ }^{1}$ A su vez, tal convergencia se ve a las claras en el capitulo I del Tractatus que tiene por título "Qué es el gobiemo real y de dónde tiene origen" (Quid sit regimen regale et unde habeat ortum). ${ }^{2}$ En este capítulo comienza una primera parte del Tractatus que llega hasta el VI. Esta primera parte responde de lleno al título de la obra: la delimitación de ambos poderes, el regio y el papal, sus orígenes y sus fines. Los restantes capítulos, del VII al XXV, versan, como promete Juan en el proemio, "sobre el poder de los pontífices eclesiásticos" (circa potestatem ecclesiasticorum pontificum, p. 69). Se trata de un verdadero tratado de potestate papae, en el cual Juan, primero, rebate puntualmente todo argumento teórico y fáctico que esgrime la tradición teocrática para sustentar "el poder sobre las cosas temporales" (dominium in rebus) por parte del papado, $\mathrm{y}$, después, se aboca de lleno al tema del momento, la deposición del papa por medio de un Concilio. ${ }^{3}$ En toda esta gran segunda parte se refleja la mano de un teólogo, buen conocedor de los textos sagrados, de la historia eclesiástica y del Derecho Canónico. A partir de estas autoridades Juan demuestra que el origen sobrenatural del "pueblo peculiar" (populus peculiaris, p. 82) que es la Iglesia no fundamenta ningún tipo de dominio material. Sobrenaturaleza y dominio o propiedad son, para Juan, términos que se excluyen. Los bienes eclesiásticos, aunque originados todos en el hecho de haber sido conferidos o donados a la Iglesia por particulares, con todo pertenecen a la comunidad y el papa es su administrador (dispensator, cap. VII, passim). Así pues, sólo es posible plantear un cierto dominio o propiedad en el ámbito natural.

\footnotetext{
M. F. GRIESBACH, "John of Paris as Representative of Thomistic Political Philosophy", An Etienne Gilson Tribute, The Marquette University Press, Milwaukee, 1959, p. 34, remarca suficientemente la dependencia de Juan para con la tradición aristotélico-tomista. J. LE CLERCO, Jean de Paris et l'Ecclesiologie du XIII' siècle, J. Vrin, Paris, 1942, p. 149, señala el hecho de que parta de principios tomistas en lo que hace a la separación de los dos ámbitos heterogéneos, cuales son la naturaleza y la sobrenaturaleza, y los lleve hasta sus últimas consecuencias. Cf. al respecto el enojo de E. Gilson La Philosophie au Moyen Age, Payot, Paris, 1962, p. 575-6. A.P. MONAHAN, John of Paris, On royal and papal Power, Columbia Univ. Press, New York, 1974, p. xliv, lo tilda de aristotélico moderado respecto del tema de la naturaleza de la sociedad politica, frente a dos extremos, representados uno por Tomás de Aquino y el otro por Marsilio de Padua. C.J. NEDERMAN, "Nature, sin and the origins of Society: the ciceronian Tradition in Medieval Political Thought" Joumal of the History of Ideas, XLIX, I (1988), p. 15, refiere la asistencia de las ideas ciceronianas para con el aristotelismo político.

2 Seguimos el texto latino según JOHANNES OUIDORT VON PARIS, Ueber königliche und päpstliche Gewalt (De regia potestate et papali), Textkritische Edition F. BLEIENSTEIN, E. Klett Verlag, Stuttgart, 1969.

3 G.C. GARFAGNINI, "II 'Tractatus de potestate regia et papali' di Giovanni da Parigi e la disputa tra Bonifacio VIII e Filippo il Bello", Concilianismo, stati nazionali, inizi dell' Umanesimo. Atti del XXV convegno storico intemazionale. Todi, Spoletto, Centro italiano di studi sull'alto Medioevo, 1990, p. 165.
} 
Ahora bien, en esta segunda parte encontramos otro pasaje (capítulo VII, $p$. 96-7) referido al origen de la propiedad privada o laica (proprietas laicorum), que aunque sea muy sucinto por hacer las veces de argumento de contrapeso para con la propiedad espiritual, con todo resulta significativo, especialmente si se lo confronta con lo dicho en la primera parte del Tractatus respecto del origen de la sociedad. Así pues, nos proponemos analizar ambos pasajes a fin de, a partir de ellos, reconstruir la idea de naturaleza e historia que maneja Juan, idea, veremos, no aristotélica pero subsidiaria a su vez de la noción aristotélica de naturaleza.

El capítulo I, acorde con su título, tiene dos partes. En la primera (p. 75, líneas 1-21) se da la definición de reino, y en la segunda (p. 75, 1. 22-p. 78, 1. 4) se demuestra su origen. Esta segunda parte, a su vez, se subdivide en dos, encabezada cada una por líneas un tanto análogas. La primera subdivisión comienza:

"Ahora bien, tal gobierno se deriva del derecho natural y del derecho de gentes. Pues ya que el hombre es por naturaleza un animal politico o civil..." (Est autem tale regimen a iure naturali et a iure gentium derivatum. Nam cum homo sit animal naturaliter politicum seu civile...).

Y la segunda subdivisión comienza:

"Y es evidente también que este gobierno se deriva del derecho natural por esto, a saber, porque el hombre es naturalmente un animal civil o político y social..." (Et patet etiam quod hoc regimen derivatur a iure naturali, ex eo scilicet quod homo naturaliter est animal civile seu politicum et sociale...).

Si confrontamos ambos pasajes resulta lo siguiente:

A

ius naturale

ius gentium

homo

animal

naturaliter

politicum seu civile

et sociale
B

ius naturale

$-.-$

homo

naturaliter

animal

civile seu politicum

Uno bien podría rápidamente equiparar ambos pasajes, porque, de un lado, ya Cicerón y el Derecho Romano identifican "ius naturale" con "ius gentium", ${ }^{4} \mathrm{y}$, de otro, "sociale", como "civile", podría corresponderse con "politicum", si no fuese porque el desarrollo de ambas partes, A y B, fuera de muy diversa índole.

En efecto, en A, Juan repite algunos de los argumentos que lee en el De regno de Tomás de Aquino (I, caps. 1-3) en favor de la monarquía como necesaria para la adquisición del bien común. Con lo cual establece Juan la instancia civil o política. En cambio, en B, y esto es lo que nos interesa, encontramos el tránsito de la vida bestial a la vida civil; cuya fuente es, fundamentalmente, Cicerón. Leemos en primer párrafo de B:

4 CICERON, De officiis III, 5, 3 "natura, id est, ius gentium". GAIUS, Institutiones I, 1 "ius gentium... est quod naturalis ratio inter homines constituit". 
"Y es evidente también que este gobierno se deriva del derecho natural por esto, a saber, porque el hombre es naturalmente un animal civil o político y social, al punto que, antes de Belo y Nino, que reinaron en un comienzo, los hombres no vivian conforme a su naturaleza como hombres, sino como bestias, sin gobierno, como cuenta en su primer libro Contra los paganos Orosio que algunos han dicho. Y Cicerón dice cosas semejantes al comienzo de su Vieja retónica y el Filósofo dice de tales en la Política que no viven como hombres sino como dioses o bestias".

Juan, pues caracteriza la naturaleza del hombre pre-civil como bestial; etapa que históricamente termina con el establecimiento de un gobierno, tal el caso de Belo y Nino. Pero de las tres citas dos están desvirtuadas. Juan no recoje la crítica contenida, justamente, en la obra de Paulo Orosio (Historiarum I, 1) a la historiografía greco-latina que hace comenzar "las acciones de reyes y pueblos... con Nino, hijo de Belo, rey de los asirios". Orosio se queja de que los historiadores se hayan olvidado o ignorado los 3184 años - según el cálculo del discípulo de Agustín - que van desde Adán a Nino, "como, dice Orosio, si el género humano hubiese vivido hasta ese momento (sc. el de Nino) a modo de animales y solo entonces por primera vez abría los ojos como golpeado y despertado a nueva luz" ${ }^{\text {. }}$. Más adelante, en el capítulo IV del Tractatus, que tiene por título "Cuál es primero temporalmente, el reino o el sacerdocio" (Quid sit prius tempore, regnum vel sacerdotium) Juan, siguiendo ahora a Agustín (De civitate Dei XVI, 17) vuelve a considerar como el primero de los reinos el asirio de Belo.

Por otra parte, la cita de Aristóteles (Politica I, 2, 1253 a 29) también queda desvirtuada, pues con ella el estagirita hace referencia a hombres que viven al margen de la "civitas" - o se es "peior quam homo, et quasi bestia" o "melior quam homo... quasi quidam deus" - y Juan la refiere a hombres anteriores al establecimiento de la "civitas". Sólo en Cicerón (De inventione I, 2) hay una afirmación tajante de "un cierto tiempo, cuando los hombres vagaban en los campos sin rumbo como bestias" (quoddam tempus, cum in agris homines passim bestiarum more vagabantur) que confirma ese estado bestial y pre-civil.

En el segundo párrafo de B encontramos el tránsito de esa etapa bestial o precivil a la civil:

"Y como los hombres no podían ser conducidos por medio de un lenguaje común, de la vida bestial a la vida en común, conveniente según su naturaleza, como se vio, los hombres que hacían más uso de la razón compadeciéndose del error de sus semejantes, comenzaron a conducirlos hacia la vida ordenada bajo alguien único por medio de razones persuasivas, como dice Cicerón, y así conducidos con ciertas leyes se unieron para vivir comunitariamente. Estas leyes, ciertamente, pueden ser llamadas aquí derecho de gentes". ${ }^{8}$

5 "Et patet etiam quod hoc regimen derivatur a iure naturali, ex eo scilicet quod homo naturaliter est animal civile seu politicum et sociale in tantum, ut ante Belum et Ninum, qui primitur regnaverunt, homines non naturaliter nec ut homines, sed more bestiarum sine regimine vivebant, ut narrat quosdam dixisse Orosius primo libro suo Contra Paganos. Et Tullius consimilia dicit in principio Veteris Rhetoricae, et Philosophus dicit de talibus in Politicis quod non vivunt ut homines sed ut dii vel bestiae" (p. 77).

Orosio, Historias, trad. E. Sánchez Salor, Gredos, Madrid, 1982.

TOMAS DE AQUINO, In libros Politicorum Aristotelis expositio, I, lec. I, 39.

"Et cum per verba communia ad vitam communem naturaliter eis convenientem, ut visum est, a vita bestiali non possent homines huiusmodi revocari, homines magis ratione utentes, eorum 
Juan traza una secuencia dada en latín por los términos "revocari-revocarerevocatos"; a saber, 1) los hombres bestiales no podían ellos mismos salirse (revocari) de ese estado y persistían en el error; 2) algunos de entre ellos más sagaces se compadecen y comienzan a hacerlos salir (revocare) por medio de argumentos persuasivos sobre la conveniencia de la vida en sociedad, y 3) una vez salidos (revocatos) se unieron con ciertas leyes, identificadas aquí por Juan con el derecho de gentes, para vivir en comunidad.

La fuente directa es, como Juan mismo refiere, el De inventione ciceroniano: Juan, entonces, suscribe el argumento del arpinate según el cual un gran hombre y sabio (magnus vir et sapiens, Cicerón De inventione I, 2) pudo, con la ayuda de la sola retórica, torcer el rumbo del género humano. A ése se le fueron sumando otros que pudieron persuadir con la elocuencia sobre aquellas cosas que habían encontrado con la razón (ea quae ratione invenissent eloquentia persuadere potuissent, ibid.), y así de un estado de error en el cual no había derecho sino que prevalecía el deseo (non ius aequabile quid utilitas haberet... propter errorem atque inscientiam caeca ac temeraria dominatrix animi cupiditas, ibid.) se pasó a otro jurídico que excluye toda violencia (ad ius voluisset sine vi descendere, ibid.). ${ }^{9}$

El otro pasaje perteneciente a la segunda parte del Tractatus dice:

"Los bienes exteriores de los laicos no han sido conferidos a la comunidad, como los bienes eclesiásticos, sino que han sido adquiridos por las personas particulares a través de su propio arte, trabajo o industria; y las personas particulares, en tanto particulares, tienen sobre ellos el derecho, el poder y la verdadera soberanía, y cualquiera puede por si, ya que es soberano, ordenarlos, disponerlos, administrarlos, retenerlos, alienarlos a su antojo, sin perjuicio de otro. Y por ello tales bienes no guardan orden o conexión entre sí ni están referidos a una cabeza común que tuviera su disposición y administración, puesto que cada uno es ordenador de sus propias cosas como le parezca. Y por ello ni el príncipe ni el papa tienen la soberanía o la administración sobre tales bienes". ${ }^{10}$

De la cita se puede colegir cinco notas que se implican:

1) el origen de los bienes laicos es el trabajo propio de cada hombre. Cada particular es dueño de su esfuerzo y del producto de ese esfuerzo. - Aunque Juan no aclare cuáles son esos bienes, los términos "bona" y "res" que utiliza tienen

compatientes errori, ad vitam communem sub uno aliquo ordinatam rationibus persuasoriis revocare conati sunt, ut dicit Tullius, et ita revocatos certis legibus ad vivendum communiter ligaverunt, quae quidem leges hic ius gentium dici possunt" (p.77-8).

9 Es exagerado pensar en un contrato de sujeción (Herrschaftsvertrag), como interpreta Walther estas "certae leges", H. G. WALTHER, Imperiales Königtum, Konziliarismus und Volkssouveränität, Wilhelm Fink Verlag, Munich, 1976, p. 160, n. 170.

10 "Exteriora bona laicorum non sunt collata communitati sicut bona ecclesiastica, sed sunt acquisita a singulis personis arte, labore vel industria propria, et personae singulares, ut singulares sunt, habent in ipsis ius et potestatem et verum dominium, et potest quilibet de suo ordinare, disponere, dispensare, retinere, alienare pro libito sine alterius iniuria, cum sit dominus. Et ideo talia bona non habent ordinem et connexionem inter se nec ad unum commune caput quod habeat ea disponere et dispensare, cum quilibe rel suae sit ordinator pro libito. Et ideo nec princeps nec papa habet dominium vel dispensationem in talibus..." (VII, p. 96-7). 
una amplísima acepción y tradición como referidos al patrimonio de los particulares (Digesto 50,16$).^{.1}$

2) y como consecuencia de 1) Los bienes laicos, así adquiridos, son también particulares. Cada individuo imprime su sello en el bien obtenido de la manera según 1).

3) y como oposición a 2) Los bienes de los laicos no son comunes ni guardan conexión $u$ orden entre sí. Los particulares, en efecto, no tienen por encima un administrador común, sea un príncipe o el papa.

4) y como consecuencia de 3) cada particular tiene el dominio absoluto sobre sus bienes y puede, por lo tanto, disponer como le plazca de ellos, pero

5) y como restricción de 4) sin perjuicio de otro.

Precisamente, en una multitud de propietarios, en la cual cada uno tiene derecho particular o privado sobre sus bienes, pueden surgir conflictos. Sigue la cita de Juan:

"Mas porque a causa de tales bienes exteriores sucede unas veces que es turbada la paz común si uno usurpa lo que es de otro y porque otras veces los hombres demasiado apegados a sus cosas no las comparten cuando lo requiera la necesidad y la utilidad de la patria, por ello fue instituido por el pueblo un príncipe que presida en tales casos como juez que discierne lo justo y lo injusto, como vindicador de las injurias y como medida en la distribución de los bienes exteriores por parte de los particulares según una justa proporción en favor de la necesidad o utilidad común." ${ }^{12}$

El primer conflicto en una multitud de propietarios particulares es la usurpación, con la cual se turba la paz común, identificada desde el capítulo I, p. 76 con el bien y fin de la comunidad civil. El segundo conflicto es la no solidaridad de algunos particulares en caso de necesidad social. Se trata de una actitud injusta que va en detrimento de los sí solidarios y que también pone en peligro la paz. La resolución de ambos conflictos se logra por la institución de un legislador.

Así pues, según Juan, el surgimiento del gobierno es posterior a la adquisición de bienes por parte de los particulares. Un príncipe, surgido y que esté por encima de los particulares, debe actuar ante el conflicto de usurpación como juez que discierne lo justo de lo injusto, fijar normas vinculantes entre los bienes privados y castigar su no cumplimiento. Respecto del segundo conflicto, el de la no solidaridad, el príncipe establece la justa medida que cada particular debe aportar, en proporción a sus bienes, en caso de necesidad. El príncipe, pues, solo tiene jurisdicción sobre el comercio o comunión entre los bienes privados en vistas al bien común.

11 Sobre ciertas analogias entre términos y concepciones que utiliza Juan y el Derecho Civil Romano: "ius in res", "dominium in rebus", "potestas", "iurisdictio", insiste J. Coleman, "Ratio and Dominium according to John of Paris and Marsilius of Padua", Preuves et Raisons a l'Université de Panis. Logique, Ontologie et Théologie au XIVe. siècle, Z. Kaluza et P. Vignaux (Eds.), Vrin, Paris, 1984, esp. p. 72.

12 "Verum quia ob talia bona exteriora contingit interdum pacem communem turbari dum aliquis quod est alteriur usurpat, quia etiam interdum homines quae suae sunt nimis amantes ea non communicant prout necessitati vel utilitati patriae expedit, ideo positus est princeps a populo qui in talibus praeest ut iudex decernens iustum et iniustun, et ut vindex iniuriarum et ut mensura accipiendo bona a singulis secundum iustam proportionem pro necessitate vel utilitate communi" (VII, 97). 
Juan distingue propiedad o dominio, propio de los particulares, de jurisdicción, propia del príncipe. De hecho, el dominio que posee cada individuo sobre sus bienes le otorga una cierta jurisdicción particular entendida como una administración "ad libitum" sobre los mismos. Mas la jurisdicción del príncipe no se funda en un dominio, porque no posee ningún tipo de dominio sobre los bienes de los particulares, sino en el hecho de que los propietarios convienen en que una instancia que esté por encima de ellos puede unirlos y conducirlos hacia el bien común o paz. El establecimiento del legislador, entonces, aparece como una necesidad de superar los conflictos entre propietarios particulares a fin de preservar la propiedad privada y en vistas al bien o utilidad común.

Que Juan tenga "in mente" aquí, en su bosquejo de la teoría de la propiedad privada, el De officiis lo demuestra el hecho de que también Cicerón coloca la usurpación como un mal antinatural ("detrahere... aliquid alteri, et hominem homini incommodo suum augere commodum, magis est contra naturam...", De officiis III, 5, 1), lo cual lleva a que la multitud se disgrege ("disrumpi necesse est eam, quae maxime est secundum naturam, humani generis societatem") (ibid.). ${ }^{13}$

Ahora bien, de la confrontación de ambos pasajes se siguen dos etapas en la evolución de la naturaleza humana, una bestial y otra civil, y entre ambas una, por así decir, de tránsito. En la bestial encontramos una multitud (multitudo) que vive bestialmente (more bestiarum/non naturaliter nec ut homines). $Y$ en tanto cada uno persigue su bien propio (bonum proprium) aparece la propiedad, aunque precaria ya que siempre se corre el riesgo de la usurpación. Ello, en última instancia, bien pudo llevar a la multitud a la ruina (dissipatur/dispergitur/non possunt revocari) si no fuera porque hubo en esa multitud algunos que tomaron conciencia del error de sus semejantes (compatientes eorum), y comenzaron a persuadirlos para que depongan esa actitud bestial (rationes persuasoriae/conati sunt revocare).

Justamente, una vez depuesta la hostilidad, esa multitud se convirtió en sociedad (societas), cuando los hombres (homo animal sociale) se unieron bajo ciertas leyes para vivir en comunidad (revocatos certis legibus ad vivendum communiter/ius naturale/ius gentium).

Comienzó la historia, finalmente, cuando esa sociedad se especificó en diferentes ciudades o reinos (civitas/regimen regale/regnum), cada uno con su propio derecho (ius civile). Los hombres (homo animal civile seu politicum) decidieron el establecimiento de un príncipe que asegurara y regulara (iurisdictio) los bienes particulares y la propiedad privada, y procurara, así, el bien común, la paz.

De esta manera, Juan completa o refuerza el naturalismo aristotélico referido a la sociabilidad del hombre con la idea ciceroniana del reconocimiento y posterior sometimiento a una cierta ley o pacto según el cual los hombres deponen su actitud bestial y se unen en comunidad. Este pacto o derecho natural o de gentes obra como tránsito entre el estado pre-civil o bestial y el derecho civil, propio de cada comunidad y que encarna el príncipe secular.

13 NEDERMAN, op. cit., sólo refiere el De inventione como utilizado por Juan - que es justamente el texto que se cita expresamente en el tratado - y no refiere el De officiis que Juan no menciona. 